\title{
Tert-butyl catechol/alkaline-treated kenaf/ jute polyethylene hybrid composites: impact on physico-mechanical, thermal and morphological properties
}

\author{
Md Rezaur Rahman ${ }^{1}$ D . Sinin Hamdan ${ }^{1}$ - Elammaran Jayamani ${ }^{1}$. \\ Akshay Kakar ${ }^{2}$. Muhammad Khusairy Bin Bakri, ${ }^{1,2}$ Fahmi Asyadi Bin Md Yusof ${ }^{3}$
}

Received: 9 March 2018 / Revised: 2 June 2018 / Accepted: 14 June 2018 / Published online: 22 June 2018 (c) Springer-Verlag GmbH Germany, part of Springer Nature 2018

\begin{abstract}
This study focuses on the effects of fiber treatment on the mechanical, morphological, physical and thermal properties of kenaf/jute/polyethylene composites, by using alkaline-treated and raw fibers. The core of jute and kenaf fibers was chopped into shorter lengths and used for composite fabrication. The composites were then subjected to tensile, water absorption, SEM, FTIR, DSC and TGA tests. According to the FTIR spectroscopy results, the alkaline treatment removed a significant amount of lignin and other impurities, especially at lower infrared band. This reduced fibers' hydrophilicity, making it more compatible with the polymer. This is evident from the SEM results, as it shows improved interfacial bonding. Therefore, the treated fiber composites, especially for $15 \mathrm{wt} \%$ composites, have higher tensile strengths, more thermal stability and higher activation energy.
\end{abstract}

\section{Introduction}

In the recent years, due to increase in the environmental awareness, the development of natural fibers has been focused on enhancing its adhesion to polymers [1-6]. According to Gowda et al. [7], natural fibers such as wood, banana, coir, kenaf, cotton, jute and sisal attracted the attention of researchers due to their potential in

Md Rezaur Rahman

rmrezaur@unimas.my

1 Faculty of Engineering, Universiti Malaysia Sarawak, Jalan Datuk Mohammad Musa, 94300 Kota Samarahan, Sarawak, Malaysia

2 Faculty of Engineering, Computing and Science, Swinburne University of Technology Sarawak Campus, Jalan Simpang Tiga, 93350 Kuching, Sarawak, Malaysia

3 Polymer Technology Section, Universiti Kuala Lumpur Malaysia - Institute of Chemical and Bioengineering Technology, 78000 Alor Gajah, Melaka, Malaysia 